\title{
UMA FONTE PARA O ESTUDO DA MIGRAÇÃO E DO MIGRANTE: OS REGISTROS DOS EVENTOS VITAIS ${ }^{1}$
}

\author{
Maria Silvia C.B.Bassanezi*
}

A fixação dos primeiros colonizadores portugueses em terras brasileiras, no início do século XVI, foi o primeiro momento da imigração internacional em direção ao Brasil, um movimento populacional que perdura até hoje. Esse movimento não foi uniforme. Conheceu períodos de maior ou menor intensidade de fluxos, envolveu pessoas oriundas de diferentes lugares e distintas condições socioeconômicas em deslocamentos forçados, subsidiados ou espontâneos.

Em escala bem menor, pessoas deixaram o Brasil em direção a outras paragens, sendo que o movimento emigratório avolumou-se a partir das últimas décadas do século $X X$. Paralelamente, um movimento interno da população, também

* Pesquisadora do Núcleo de Estudos de População (NEPO/UNICAMP), bolsista PQ/CNPq e pesquisadora do Projeto Temático/FAPESP Observatório das Migrações em São Paulo (Fases e faces do fenômeno migratório no Estado de São Paulo), coordenado por Rosana Baeninger e desenvolvido junto a esse núcleo.

${ }^{1}$ Um texto mais amplo sobre o uso dos registros paroquial e civil de batismo/nascimento, casamento e óbito na pesquisa histórica foi escrito pela autora e publicado (BASSANEZI, M. S. Os eventos vitais na reconstituição da história. In PINSKY, C. B.; LUCA, T. R. de (orgs.) O Historidor e suas fontes. São Paulo: Contexto, 2009, p. 141-172). O presente texto retoma esse tema visando principalmente o uso desse corpo documental para os estudos migratórios. 
$|90|$

Uma fonte para o estudo da migração e do migrante:...

com diferentes intensidades, motivações e direções variadas, ocupou e transformou o espaço brasileiro ao longo de mais de quinhentos anos.

Nas últimas décadas do século XX e nesse século XXI, os movimentos migratórios intensos abrem cada vez mais espaço na agenda dos estudiosos e das autoridades governamentais. Ao mesmo tempo, as migrações dos séculos anteriores e primeira metade do século XX, chamadas "históricas", continuam a interessar os estudiosos, que, agora, perseguem novos temas e buscam novas fontes e metodologias em suas análises e, dessa forma, ampliam o conhecimento contribuindo, inclusive, para o entendimento dos movimentos populacionais contemporâneos.

Assim, relacionar os movimentos populacionais do passado com os mais recentes passa a ser inevitável. Pesquisas têm mostrado que a mitologia sobre a migração do passado e a percepção que muitas pessoas têm hoje dessa migração marca profundamente como a nova migração é vista. Além disso, estudos comparativos passado/presente têm ajudado a evitar que aspectos particulares da migração atual sejam super ou subvalorizados se considerados por si só; eles apontam diferenças e também as muitas similaridades e continuidades entre os movimentos. Tais estudos contribuem, inclusive, do ponto de vista teórico, avaliando, por exemplo, se conceitos e modelos elaborados à luz da migração atual são únicos do momento atual ou podem ser também do passado. Enfim, as comparações permitem ver o que é realmente novo e o que não é nos movimentos populacionais mais recentes (FONER, 2000).

Entre as fontes de informações mais ricas para o estudo comparativo dos migrantes e das migrações dos séculos anteriores com as mais atuais estão o registro paroquial e civil, de batismo/ nascimento, casamento e óbito - são os chamados registros vitais. Este texto busca mostrar as potencialidades e dificuldades no trabalho com tal conjunto documental para o entendimento dos fluxos migratórios, internacionais e internos, do passado e do presente. 
É fato que em tais registros - elaborados e conservados pela Igreja Católica, por algumas das Igrejas Reformistas e pelo Registro Civil de Pessoas Naturais - a migração e o migrante nacional ou estrangeiro, enquanto tais, não constituem o objeto direto de sua produção. No entanto, seus dados podem ser recuperados através desses registros, porque, entre as informações presentes nesses documentos, encontram-se a nacionalidade e/ou naturalidade das pessoas envolvidas e o local onde residem, no momento em que ocorreu o evento. Como se sabe, em princípio, todos os nascimentos, casamentos e falecimentos ocorridos em um determinado local se encontram registrados nesses documentos. Mesmo que, em certos momentos e localidades, uma parcela de nascimentos, casamentos e óbitos por algum motivo não tenham sido anotados, pode-se dizer que tais registros constituem-se em fontes democráticas, pois de fato incluem todos os setores da sociedade: homens e mulheres, ricos e pobres, brancos, negros e índios, filhos legítimos e ilegítimos, crianças expostas ou enjeitadas, escravos e libertos (antes de 1888, no Brasil), muitos deles migrantes (BASSANEZI, 2009).

\section{$\mathrm{O}$ registro paroquial}

O registro paroquial de batismo, casamento e óbito originalmente utilizados pelos demógrafos historiadores para calcular as tendências históricas da reprodução humana, construir medidas de fecundidade, nupcialidade, mortalidade e observar o crescimento populacional e a formação das famílias - têm se mostrado importantes também para o conhecimento de outros aspectos da história social e cultural. A história da família, da mulher, da escravidão, das mentalidades avançou muito com a utilização desse corpo documental.

Nos estudos de caráter mais demográfico, e em particular da migração, esses registros produzidos pela Igreja, particularmente, têm um peso muito grande, pois guardam informações de uma época em que não existia o Registro Civil - 
$192 \mid$

Uma fonte para o estudo da migração e do migrante:...

em que não havia a separação a entre Estado e Igreja - ou seja, o Brasil do início da colonização portuguesa à Proclamação da República. São úteis também para os estudos históricos de períodos em que os censos regionais e nacionais são poucos, trazem muitas lacunas ou não são confiáveis. Mas eles podem ser utilizados para período posterior dependendo do que se quer conhecer, como, por exemplo, persistência ou mudança nas práticas religiosas, culturais que os migrantes trouxeram ou adquiriram no novo local de moradia.

De acordo com as normas estabelecidas pela Igreja Católica Romana, na ata de batismo devem constar: a data do evento, nome completo do batizando, nome dos pais, filiação legítima ou ilegítima, local de residência dos pais ou responsáveis, o nome de pelo menos um padrinho (melhor dois), a assinatura do sacerdote. Vários outros aspectos considerados importantes e dignos de menção também podem ser encontrados em tais registros: se a criança foi concebida dentro ou fora de um casamento formal, se os pais são conhecidos ou não, se batizada em casa, por estar em perigo de morte; além desses, informações como a condição social dos pais e, mais raramente, a naturalidade dos pais e nomes dos avós maternos e paternos.

O registro paroquial de casamento, por sua vez, deve conter: a data do casamento, o nome de cada cônjuge e sua filiação, residência, naturalidade e a assinatura do sacerdote. No caso de casamento de viúvo ou viúva, a declaração de viuvez do cônjuge, com o nome do(a) primeiro(a) esposo(a); se os cônjuges estavam incursos nos impedimentos "graves" ou "leves" determinados pelo Código Canônico da Igreja Católica. Com o tempo, foram assinalados também: o local de realização do casamento, a idade dos cônjuges, a condição social dos nubentes, os nomes das testemunhas acompanhados de alguma característica das mesmas, como, por exemplo, o estado civil e o título. Em se tratando de nubentes escravos, esses registros anotam o nome do proprietário e os relativos a imigrantes trazem a nacionalidade e, muitas vezes, a paróquia de origem dos mesmos. No caso de filhos de imigrantes nascidos no Brasil, no registro de casamento pode ser encontrada 
a nacionalidade dos pais dos nubentes. Quando os cônjuges pertencem às categorias sociais e econômicas mais elevadas as anotações são mais completas, incluem os nomes de avós maternos e paternos de cada cônjuge, a paróquia e as dioceses de nascimento e moradia e, além do vigário e das testemunhas, outras pessoas presentes assinam o registro.

\section{Registro paroquial de casamento}

Aos vinte e três dias de dezembro de mil novecentos e vinte, na Igreja de São José da Vila Industrial perante o [ilegível] Nicolau Vam Roogem e das testemunhas Francisco Molina e Vicente de Moraes canonicamente proclamado e não constando impedimento algum receberam em matrimônio Demenso Canteiro e Vicentina Bobbo. Elle solteiro, hespanhol, natural de Valencia, filho de Julião canteiro e Adela Luiza Alonso. Ella solteira, brasileira, natural de Araras de 19 annos filha de João Bobbo e Maria de Moraes. Ambos residentes neste Curato. [assinatura do padre]

Os registros de óbito são mais simples e as normas não tão rigorosas. Eles anotam a data do falecimento, o nome do morto, seu estado civil. No caso de solteiros, os pais são nomeados, ou o fato de ter sido "exposto" ou ser filho "natural". Para os falecidos(as) casados(as) e viúvos(as) trazem o nome do esposo(a). Em muitas paróquias assinalam-se a naturalidade do morto, a nacionalidade em se tratando de estrangeiro, sua idade, a atividade ocupacional ou profissão exercida, a causa da morte e se o morto deixa testamento. Sendo escravo, o nome do proprietário vem também registrado. Em várias paróquias, as condições do enterramento vêm por vezes mencionadas: tipo e cor da mortalha ou do caixão (século XIX), local do enterramento, algum detalhe cerimonial. Depois da implantação do registro civil, o registro paroquial de óbito foi perdendo sua importância e com o tempo deixou de feito. 


\section{Registro paroquial de óbito}

Aos três de Fevereiro de mil oitocentos e cincoenta e três falleceo com todos os sacramentos José Custódio Leite [Ilegível] natural de Parnahyba de quarenta anos de idade casado com Barbara Paes de Barros envolto em habito preto e capa branca jaz no cemitério [Assinatura do vigário]

No decorrer do tempo, a legislação eclesiástica foi acrescentando novas informações ou suprimindo outras anteriormente existentes. No entanto, a abrangência das informações presentes nos registros de batismo, casamento e óbito, em que se pesem as normas estabelecidas, estiveram sempre na dependência do zelo do vigário em anotá-las, ampliá-las ou suprimi-las (MARCÍLIO, 2004 e 2008; BASSANEZI, 2009). Registro Civil.

Embora as origens do registro civil no Brasil datem da primeira metade do século XIX e na segunda metade desse século houvesse um esforço para regulamentá-lo, foi somente com a Proclamação da República que ele passou, definitivamente, a ser implantado. Assim mesmo, nos anos iniciais da República, demorou muito para que a população fosse conscientizada da necessidade de registro civil e os registros realizados pela Igreja continuaram a ter efeito legal ainda por algum tempo. No decorrer do século XX uma série de decretos e leis trouxe novas modificações jurídicas em termos de registro civil, mas sem alterações significativas no quadro das informações exigidas para o registro dos eventos vitais.

As informações contidas nas atas do registro civil de nascimento podem ser agrupadas em: - dados do registro: número, data e local; dados sobre o nascido: nome e prenome, data do nascimento, lugar do nascimento (geográfico e funcional), sexo, natureza do parto (gêmeos ou não), filiação (legítima ou ilegítima), cor (depois de 1928), nasceu vivo ou nasceu morto, morreu no ato ou logo depois do parto; dados sobre os pais: nome, naturalidade, 
profissão, residência, local do casamento, idade da mãe no momento do parto (pós 1974); outros dados: ordem de filiação de outros irmãos de mesmo prenome, nome de avós materno e paterno, nome, prenome, profissão e residência das testemunhas.

\begin{abstract}
Registro civil de nascimento
Aos nove de Dezembro de mil novecentos e cinco, nesta cidade, em meu cartório, compareceu David Jose Antonio declarando que a dous do corrente mez as nove horas da noite, na fazenda Cascata nasceu a creança de cor parda do sexo masculino que terá o nome de Sebastião, filho legítimo dele declarante, aministrador agrícola e de Emilia Maria dos Santos, brasileiros naturaes esta deste Estado e aquelle do Rio de Janeiro, casados nesta cidade e residentes na referida fazenda, avós paternos Jose Antonio e Clemencia e maternos Bento da Cunha e AnnaMaria dos Santos. Nada mais declarou. Oque para constar lavrei este ato que lido, assignam João da Rocha Campos, a rogo do declarante por não saber escrever e testemunhas. Eu escrivão e official [seguem as assinaturas]
\end{abstract}

\section{Registro civil de nascimento de filho de estrangeiros} Aos treze de Dezembro de mil novecentos e cinco nesta Cidade em meu cartório compareceu Narde Fiori Giovanne, declarando que a onze do corrente mez as cinco horas da manhã, no bairro da Guanabara, casa número oito da rua Raphel Sampaio, nasceu a creança do sexo feminino que lido digo que terá o nome de Amelia, filha legitima do declarante, negociante, e de Henriqueta Pintor, esta hespanhola e italiano aquelle, casados nesta Cidade e residentes na referida casa, avos paternos Jorge Narde e Lucia Guarnieri e maternos Antonio Pintor e Rosalia Meirelles. Nada mais declarando que para constar lavrei este ato declarou digo ato que lido assigno com o declarante e testemunhas. Eu escrivão e official [seguem as assinaturas] 
|96|

Uma fonte para o estudo da migração e do migrante:...

Nos registros de casamento, encontram-se basicamente: dados do registro: número, data e local; dados dos cônjuges: nome, filiação (legítima ou ilegítima), idade, naturalidade, residência, profissão; dados sobre os pais: nome e às vezes a data de nascimento, profissão, domicílio e residência; dados das testemunhas: nome, idade, profissão, residência e assinatura; "assinatura a rogo" de testemunha, quando um, ou os dois cônjuges não sabiam ler e escrever; o regime de casamento (se ou não com comunhão de bens) e outros dados: se for o caso, os filhos tidos antes do casamento, seus nomes e idades; se forem parentes, o grau de parentesco; se viúvo o nome do cônjuge falecido.

Nos registros de óbitos as informações também podem ser agrupadas em: dados do registro: número, data e local; dados sobre o óbito: nome e prenome, data do falecimento, lugar do falecimento (geográfico e funcional), sexo, idade, cor (depois de 1928), estado civil, profissão, naturalidade, domicílio ou residência do morto; dados sobre os pais: nome e prenome naturalidade, profissão, residência; dados sobre os filhos: nome e prenome, idade; outros dados: tipo de morte, causa da morte, lugar do sepultamento, nome do cônjuge e cartório do casamento, se deixou bens ou herdeiros menores e interditos (depois de 1928) (ALTMAN e FERREIRA, 1979; HARKETT, 1996; BASSANEZI, 2009). 


\section{Registro civil de casamento}

Aos vinte e três dias de Abril de mil nove centos e quatro nesta cidade de Campinas, districto de Santa Cruz, em a sala do cartório de Paz a rua Sacramento as oito horas da manhã, perante o juiz de casamento Doutor João de Assis Lopes Martins, comigo escrivão e oficial seu argo adiante nomeado e satisfeitas as exigências legais ao auto receberam-se em matrimonio segundo o regimen comum os contraentes Marsan Giovanni e Baldin Giovanna aquele com vinte e dois annos de idade, natural de Venesia, colono agrícola e esta com vinte annos, natural de Trevizo, ambos italianos solteiros e residentes neste districto, sendo filhos legítimos de Marsan Nicola e Morigno Santa e a segunda de Baldin Fillipo e Bellato Rosa, estes e aquelles residentes neste districto. Testemunharam perante o act o Stradiatto Giuseppe com trinta anos de edade, sapateiro e [ilegível] Gaitto com vinte e sete anos de edade, negociante e [ilegível] Vicenzo com vinte e oito anos de edade, colono agrícola todos residentes neste districto. Em firmeza do que eu Manoel Carlos de Toledo Leite escrivão e official lavrei este acto que vai por todos assignados fazendo a rogo da contraente que não sabe escrever a ultima testemunha mencionada depois de lido e achado conforme [seguem as assinaturas]

\section{Registro civil de óbito}

Aos treze de abril de mil oitocentos e noventa e seis, nesta cidade de Campinas, districto da Conceição, em cartório compareceu José Felix e exhibindo atestado do DrThomaz Alves Filho declarou: - que a quatro do corrente mez, às quatro horas da manhã falleceo de febre amarela Luiza Joaquina italiana, casada com cessenta e oito anos de edade e foi sepultada no cemiterio publico. E para constar faço este termo.[segue assinatura] 
|98|

Uma fonte para o estudo da migração e do migrante:...

\section{As potencialidades da fonte}

Como o leitor atento pode observar esses registros são propícios a múltiplas leituras pela riqueza de informações e pelas muitas possibilidades de pesquisa que oferecem, não só de uma perspectiva demográfica, mas também sociocultural. Muitas pesquisas já realizadas no Brasil, que utilizaram tais registros, confirmam esta afirmação².

${ }^{2}$ Pesquisas realizadas que se valeram dos registros dos eventos vitais: ANDREAZZA, M. L. Paraíso das delícias: estudo de um grupo ucraniano. Curitiba, 1996. Tese de Doutorado. Universidade Federal do Paraná. BALHANA, A. P. Famílias Coloniais: fecundidade e descendência. Curitiba: UFPr/ SCHLA/Departamento de História, 1977. (Tese apresentada ao Concurso para Professor Titular de História da América). BACELLAR, C. de A. P. Os senhores da terra: família e sistema sucessório entre os senhores de engenho do Oeste Paulista, 1765-1855. Campinas: Centro de Memória/ UNICAMP, 1997. BACELLAR, C.de A. P. Viver e sobreviver em uma vila colonial: Sorocaba, séculos XVIII e XIX. São Paulo: Annablume/FAPESP, 2001.BASSANEZI, M.S.C.B. Considerações sobre os estudos do celibato e da idade ao casar no passado brasileiro. Anais do V Encontro Nacional de Estudos Populacionais. Belo Horizonte:ABEP, 1994. BASSANEZI, M.S.C.B. O casamento na colônia no tempo do café. Anais do VI Encontro Nacional de Estudos Populacionais. Belo Horizonte, ABEP, 1988. BASSANEZI, M.S.C.B. Famílias em movimento: São Paulo (Brasil) 1890-1930 (no prelo). BOTELHO, T. R. Famílias e escravarias: demografia e família escrava no Norte de Minas Gerais no século XIX. São Paulo, 1994, Dissertação de mestrado. Faculdade de Filosoifia, Letras e Ciências Humanas, Universidade de São Paulo. BRÜGGER, S. M. J. Minas patriarcal: família e sociedade (São João Del Rei - séculos XVIII e XIX). São Paulo: Annablume, 2007. BURMESTER, A.M. Population de Curitiba au XVIIIe. Siècle. Tese (doutorado), Universidade de Montreal, 1981. COSTA, I. Del N.; GUTIÉRREZ, H. Notas sobre casamentos de escravos em São Paulo e no Paraná (1830). História: questões e debates, Curitiba, v. 5, n. 9, p. 313-321, dez.1984. CUNHA, M. F. Fogos e escravos da Franca do Imperador no século XIX. Campinas, 2005. Dissertação(Mestrado). Faculdade de Filosofia e Ciências Humanas, Universidade Estadual de Campinas/ 
Eles se prestam tanto às análises de caráter qualitativo como quantitativo; análises em nível micro ou macro e, em sendo uma fonte nominativa (pois trazem nomes das pessoas) se prestam a cruzamentos entre si e com outras fontes nominativas ou não. Devido à sua abrangência temporal, os registros ajudam no entendimento dos processos demográficos, sociais e culturais, das permanências e mudanças, das tendências seguidas no decorrer do tempo pela migração e pelos migrantes. Possibilitam a reconstituição de famílias, das redes sociais estabelecidas (uma

UNICAMP. CUNHA, M. F. Demografia e família escrava. Franca- SP, século XIX. Campinas, 2009. Tese (Doutorado). FARIA, S. C. A colônia em movimento: fortuna e família no cotidiano colonial. Rio de Janeiro: Nova Fronteira, 1998. GUTIERREZ, H. Demografia escrava numa economia não-exportadora: Paraná, 1800-1830. Estudos Econômicos, São Paulo, v. 17, n. 2, 1897. HAMEISTER, M. D. Para dar calor à nova povoação: estudos sobre estratégias sociais e faamiliares a partir dos registros batismais da vila do Rio Grande (1738-1763). Rio de Janeiro, 2006 Tese (doutorado em História Social). IFCS, Universidade Federal do Rio de Janeiro. KÜHN, F. Rio Grande do Sul Colonial: população e sociedade na segunda metade do século XVIII. In II Seminário de História Quantitativa e Serial. Belo Horizonte: PUCMINAS, 2001. MACHADO, C. A trama das vontades: negros, pardos e brancos na construção da hierarquia social do Brasil escravista. Rio de Janeiro: Apicuri, 2008.MARCíllO, M. L. A cidade de São Paulo. Povoamento e População 1750-1850, São Paulo: Pioneira, 1974. MARCILIO, M.L. Caiçara: terra e população. São Paulo: Paulinas; Cedhal, 1986. NADALIN, S.O. Une paroise germanique au Brésil: La Communauté Évangelique Luthériènne à Curitiba entre 1866 et 1969. Paris, França, 1978. Tese (Doutorado) - École dês Hautes Études em Sciences Sociales; NADALIN, S.O. “João, Hans, Johann, Joahannes: dialética dos nomes de batismo numa comunidade imigrante". Revista História Unisinos. Sã Leopoldo, 2007. ROCHA, C. M. Histórias de famílias escravas: Campinas, século XIX. Dissertação (Mestrado). Faculdade de Filosofia, Ciências Humanas/UNICAMP, 2004. SCOTT, A. S. V. Família, formas de união e reprodução social no noroeste português (séculos XVIII e XIX). Guimarães: NEPS;Universidade do Minho, 1999. TEIXEIRA, P. A formação das famílias livres e o processo migratório: Campinas (1774-1850). São Paulo, 2005. Tese de doutorado - Departamento de História, USP/FFLCH. 
| 100 |

Uma fonte para o estudo da migração e do migrante:...

vez que eles trazem também o nome dos pais, avós, padrinhos, testemunhas, oficiantes, pessoas que assinam "a rogo" pelos que não sabem ler ou escrever) e de outros aspectos que marcam as vidas dessas pessoas e grupos, por exemplo, hierarquias sociais, práticas religiosas.

Através desses registros, é possível recompor uma parcela do mundo da infância, da família, da mulher, do trabalhador migrante; conhecer vários aspectos relativos ao casamento (endogamia ou exogamia, idade ao casar), ao óbito (idade ao falecer, causa morte, se com ou sem assistência médica) entre os migrantes e os relativos ao nascimento, casamento e óbito de seus filhos na terra hospedeira. Com eles é possível recompor as características do movimento migratório em termos de volume, sexo, idade, nacionalidade, naturalidade, estado conjugal, filiação legitima e ilegítima, ocupação, condição social, instrução (alfabetizado, analfabeto); verificar a existência de certos padrões específicos de comportamento demográfico ou sociocultural entre os imigrantes, com relação à ilegitimidade, ao compadrio, às escolhas matrimoniais, à mortalidade. A partir de tais registros pode ser visualizada com bastante clareza a movimentação espacial das populações, assim como a sazonalidade dos eventos vitais, as taxas de natalidade, nupcialidade, mortalidade, que refletem costumes, tradições, mentalidade religiosa, atividades econômicas, condições climáticas, sanitárias e biológicas. Mais ainda, permitem conhecer aspectos diversos da vida do migrante vis a vis aos nativos da terra hospedeira e àqueles que permaneceram na terra de origem.

\section{O trabalho com essa fonte}

A bem sucedida experiência dos historiadores que trabalharam com os registros paroquiais em estudos de Demografia Histórica e História Social, a partir de meados do século XX - quando Louis Henry demonstrou as potencialidades desses documentos para os estudos demográficos, criando uma metodologia para a coleta e análise das informações contidas nos 
registros paroquiais franceses - animam novas pesquisas com este corpo documental e também com o registro civil ${ }^{3}$.

A coleta e o manejo das informações contidas nesse corpo documental exigem um dispêndio de tempo grande, atenção e paciência do pesquisador, exige um trabalho de equipe. A primeira fase de levantamento, análise crítica, transcrição dos dados, que precede a análise propriamente dita, é lenta e árdua. No entanto, vale à pena a empreitada, pelas inúmeras possibilidades que abre para pesquisas que têm como tema a migração.

A exploração desses documentos lança mão de metodologias, técnicas e determinados cuidados preconizados por Henry e, posteriormente, ampliados por outros estudiosos tanto da demografia, como de outras áreas do conhecimento.

Primeiramente é preciso trabalho prévio para descobrir onde se acham os livros da paróquia ou em que cartório do registro civil ou arquivo, da localidade privilegiada pelo estudo, se eles existem. Localizado o corpo documental, é preciso verificar se a coleção abrange todo o período a estudar, se está bem conservada, se não faltam muitos registros e se os que se encontram manuscritos são legíveis. Assim, é preciso fazer uma análise crítica rigorosa da documentação existente, de seus dados, em bases científicas e utilizar metodologias adequadas para evitar comprometer a pesquisa e seus resultados, em função de eventuais

\footnotetext{
${ }^{3}$ A metodologia, criada por Henry, incluí levantamento anônimo e nominativo dos dados, e, neste caso, também um posterior cruzamento dessas informações nominativas em uma ficha de família, possibilitando a reconstituição de família. Essa metodologia está minuciosamente descrita em um manual publicado na França, em co-autoria com Michel Fleury, e em outro, já traduzido para o português, sobre técnicas de análise demográfica. FLEURY M.; HENRY, L. Nouveau Manuel de dépouillement et d'exploitation de l'etat civil ancien. Paris: INED, 1985. HENRY, L. Técnicas de análise em Demografia Histórica. Tradução de Altiva P. Balhana e Jayme A. Cardoso. Curitiba: UFPr, 1977.
} 
|102|

Uma fonte para o estudo da migração e do migrante:...

lacunas ou conclusões apressadas e equivocadas. Ter noções de estatística, de informática, capacidade de construir e "ler" tabelas e porcentagens e conhecer determinados programas de computador (conforme as questões de cada pesquisa) são fundamentais. No caso da pesquisa não trabalhar com o universo, mas com uma amostra, esta deve ser selecionada com todo rigor estatístico, cujas regras o pesquisador deve obedecer.

Nas últimas décadas, os avanços tecnológicos atrelados aos trabalhos individuais e, sobretudo, os de equipe e aos recursos disponíveis nas universidades e centros de pesquisa (scanner, maquinas fotográficas digitais, máquinas digitalizadoras, micro computadores e softwares diversos) vêm animando os pesquisadores a explorar os registros vitais para o conhecimento dos processos migratórios e da vida sociocultural dos migrantes. Esses avanços permitem tratar com novo fôlego e mais rapidamente a informação massiva contida nesse volumoso corpo documental. O uso da informática possibilita fazer cruzamentos antes quase impossíveis, possibilita a realização de cálculos e análises de tendências e processos com maior precisão em menor espaço de tempo. Possibilita ampliar a representatividade dos eventos analisados e dar às análises uma base documental maior.

O sucesso do trabalho com os registros dos eventos vitais, certamente não pode prescindir do cruzamento com outras fontes que trazem elementos para o conhecimento da migração e do conhecimento já produzido sobre esse tema. O sucesso será muito maior se contar com uma equipe multidisciplinar.

\section{As pedras no meio do caminho}

Em que se pesem todas as opções temáticas que essas fontes apresentam para os estudos da migração e dos migrantes e dos avanços da informática que possibilitam trabalhar com maior volume de dados e mais rapidamente, o estudioso que se aventura ao trabalho com as mesmas encontra "pedras no meio do caminho" às quais precisa estar alerto. 
O acesso a essas fontes nem sempre é fácil, depende de autorização e em muitos casos também da boa vontade de seus responsáveis".

É preciso não esquecer a possibilidade de existência de subnumeração dos eventos vitais. Crianças nasciam e/ou morriam, por exemplo, sem que houvesse algum registro de sua existência, assim como muitos adultos não legalizavam suas uniões ou não tiveram sua morte anotada. No que diz respeito aos registros paroquiais, o limite também está no fato de congregarem apenas a população católica ou de outra Igreja que adotou sistema semelhante para registrar os eventos vitais de seus seguidores, como, por exemplo, a Igreja Luterana.

É preciso estar alerto para os respectivos desdobramentos territoriais das freguesias, distritos e municípios e de alterações dos nomes das localidades. É muito comum na história brasileira municípios se desmembrarem, criando novos municípios, outros desaparecem e entre esses últimos vários serem recriados. É preciso evitar que a realidade reconstruída através dos registros não apresente vieses vinculados a esses aspectos e também aos próprios documentos que sobreviveram e que estão disponíveis à pesquisa.

Como até décadas mais recentes esses registros eram manuscritos, muitos deles são de difícil leitura. Por outro lado, observa-se que no Brasil como em Portugal, a adoção dos

\footnotetext{
${ }^{4}$ A Igreja de Jesus Cristo dos Santos dos Últimos Dias (mórmons) microfilmou os registros das paróquias e dos cartórios de uma parcela ponderável de localidades brasileiras, o que, de modo geral, abrange o período que vai da criação das respectivas freguesias ou paróquias à década de 1930. Cópias desses microfilmes foram entregues aos responsáveis pelos livros e, dessa forma, é possível que muitas paróquias, acervos das dioceses, cartórios ou arquivos históricos guardem estes microfilmes e possam disponibilizá-los para os pesquisadores interessados. O site para buscar informações sobre microfilmes é: ht t p://www.familysearch.org/Eng/Library/fhlcatalog/ supermainframeset.asp? display=localitysearch $\&$ columns $=*$,0,0. O site para buscar informações sobre famílias (bases de dados já digitadas) é: http://search.labs.familysearch.org/recordsearch/\# $p=0$.
} 
| 104 |

Uma fonte para o estudo da migração e do migrante:...

sobrenomes, ou nome de família, não seguiu uma única regra de transmissão e em se tratando de estrangeiros não portugueses, $o$ "aportuguesamento" do nome ou a grafia errada também que dificulta o cruzamento de informações nominativas. Também, não se pode esquecer que esses documentos expressam muitas vezes a subjetividade das pessoas que coletam ou prestam as informações, da importância que elas dão às mesmas. Para solucionar tais questões muitas vezes é preciso contar com a ajuda de um paleógrafo, de um linguista, de um conhecedor da história local e de se recorrer ao cruzamento de informações em outros registros ou em outras fontes nominativas para obter a informação correta.

Ainda é preciso assinalar que os registros de batismo/ nascimento, casamento e óbito são mais propícios aos estudos sobre imigração e imigrante, sobre aqueles que "entram" em uma dada localidade, do que sobre os que emigram, os que "partem", embora seja possível captá-los em parte com técnicas e metodologias específicas e sofisticadas da demografia ou da matemática e estatística.

Por fim, a massa volumosa de registros de um dado local e a lentidão com que se processa esse trabalho de levantamento e transcrição das informações, mesmo com todos os recursos de informática disponíveis, acaba por restringir a pesquisa a espaços de análise menores.

\section{Um desafio}

No campo das migrações internas no Brasil uma das lacunas observadas é a quase ausência de pesquisas mais profundas sobre os movimentos migratórios ocorridos no Brasil antes de meados do século XX. Isso é lamentável, em vista das potencialidades desse tipo de análise abre, para a própria compreensão dos processos econômicos, sociais e politicos que forjaram a atual nação brasileira (MARTINE, 1990, p. 16). Passadas quase duas décadas dessa constatação de Martine, muito pouco se avançou sobre esta temática.

Agora, na passagem da primeira para a segunda década do século XXI, o NEPO - através do Projeto Temático FAPESP, 
Observatório das Migrações em São Paulo (Fases e faces do fenômeno migratório no Estado de São Paulo) 5 - colocou-se, entre outros, o desafio de buscar nos registros paroquial e civil dos eventos vitais indicações que possam preencher aquela lacuna. Dessa forma, procura-se ampliar o conhecimento sobre a migração interna em direção ao Estado de São Paulo, sobre a intensa mobilidade espacial que se deu no interior território paulista nesse período, e, paralelamente, trazer novos ingredientes ao conhecimento da imigração internacional que se dirigiu a esse estado naquele período sobre a qual se conhece um pouco mais.

Em favor do uso dos registros dos eventos vitais nos estudos migratórios, é preciso destacar que as estatísticas existentes (censos, anuários, boletins, relatórios), que trazem informações para o Estado de São Paulo, são um pouco mais pródigas com relação à imigração internacional e parcimoniosas quando tratam da imigração oriunda em outros estados brasileiros, o que significa conhecer fragmentos da migração interprovincial/estadual. Além disso, nada informam sobre a intensa mobilidade espacial de nativos e estrangeiros dentro do território paulista, no século XIX e primeiras décadas do século XX, em virtude da expansão da agricultura de exportação, da rede ferroviária, do processo de urbanização e industrialização que se verifica no período. Nesse sentido, os registros dos eventos vitais que contém a nacionalidade, naturalidade e local de residência, juntamente com outras informações importantes (sexo, idade, estado conjugal, ocupação etc.) dos personagens envolvidos nesses eventos podem trazer uma grande contribuição para a compreensão desses processos migratórios, não só de caráter quantitativo, mas também qualitativo.

A pesquisa que vem sendo desenvolvida no NEPO, com a participação de pesquisadores e alunos da UNICAMP, UNESP e

${ }^{5}$ O ProjetoTemático Observatório das Migrações em São Paulo (Fases e faces do fenômeno migratório no Estado de São Paulo) conta com uma série de Estudos Temáticos que se agrupam em duas Linhas Temáticas: I. Migrações internas e internacionais na formação social paulista: uma perspectiva histórica; II Migrações internas e internacionais contemporâneas em São Paulo. 
|106 |

Uma fonte para o estudo da migração e do migrante:...

UFSCar, que tem como fonte básica os registros dos eventos vitais, privilegiou os municípios de Campinas e São Carlos. Estes municípios foram escolhidos devido a fatores que tornam a pesquisa viável e com maior chance de sucesso: os registros paroquial e civil de batismo/nascimento, casamento e óbito de Campinas encontram-se disponíveis à pesquisa em forma de microfilme, nos arquivos da UNICAMP (AEL e CMU), os registros paroquiais de São Carlos encontram-se na Cúria Diocesana local e na Fundação Pró-Memória de São Carlos as habilitações de casamento do registro civil; por outro lado, já existe de uma bibliografia ampla sobre a história desses municípios e os pesquisadores envolvidos já desenvolveram outros trabalhos que privilegiaram esses municípios e, portanto, são conhecedores do contexto histórico dos mesmos. Além disso, o referido projeto temático abarca outras pesquisas que focalizam aspectos da migração contemporânea nacional e/ou estrangeira focando esses municípios e o Estado como um todo, possibilitando comparações passado/presente.

No momento, esta pesquisa encontra-se em fase bastante adiantada de digitalização dos fotogramas dos microfilmes e da organização de um banco com as cópias dos originais dos registros. Iniciou-se a montagem de um banco de dados informatizado com as informações contidas nos registros, com o uso do softwear SPSS.

A análise dos dados priorizará num primeiro momento o conhecimento das características do movimento migratório nesses municípios - procedente do próprio território paulista, de outras províncias/estados do país e de outros países - em termos de volume, sexo, idade, nacionalidade, naturalidade, estado conjugal, filiação legitima e ilegítima, ocupação, condição social, instrução (alfabetizado, analfabeto); conhecimento das taxas de natalidade, nupcialidade, mortalidade, da existência de padrões específicos de comportamento demográfico entre os migrantes, como, por exemplo, em relação às escolhas matrimoniais, à mortalidade, à sazonalidade dos eventos, buscando também conhecer seus condicionantes e suas implicações. Sempre que possível, a pesquisa 
buscará comparar com os padrões demográficos observados pelos migrantes com aqueles verificados entre os nativos da terra hospedeira e/ou aqueles que permaneceram na terra de origem.

A pesquisa não deve parar por aí. O banco de dados tem uma riqueza de informações e abre-se a outros estudos, demográficos e socioculturais. No futuro este banco estará disponível a outros pesquisadores; novas pesquisas e parcerias serão bem-vindas.

\section{Referências}

ALTMANN, A.M; FEREEIRA, C.E. de C. - Evolução do censo demográfico e registro civil como fontes de dados para análise da fecundidade e mortalidade no Brasil. Revista Brasileira de Estatística. Rio de Janeiro, v. 40, n. 160, 339-454, out/dez. 1979.

BASSANEZI, M.S.C.B. Os eventos vitais na reconstituição da história. In PINSKY, C.B. e LUCA, T. R. de O historiador e suas fontes. São Paulo: Contexto, 2009, p. 141-172.

FONER, N. From Ellis Island to JFK: New York's two great waves of immigration. New Haven and London: University Press; New York: Russell Sage Foundation, 2000.

HAKKERT, R. Fontes de dados demográficos. Belo Horizonte: ABEP, 1996.

MARCÍLIO, M.L. Os registros Paroquiais e a História do Brasil. Varia História, n. 31, jan.2004.

Registros Paroquiais como fontes seriais que escondem realidades sociais inusitadas. In SCOTT, A. S.V.; FLECK, E.C.D. (Org.) A Corte no Brasil: população e sociedade no Brasil e em Portugal no início do século XIX. São Leopoldo (RS): Oikos; Editora Unisinos, 2008.

MARTINE, G. As migrações de origem rural no Brasil: uma perspectiva histórica. In NADALIN, S.O.; MARCÍLIO, M.L.; BALHANA, A.P. (orgs.) História e população: estudos sobre a América Latina. São Paulo; FSEADE, 1990, p. 16-24. 